\title{
PARCELAMENTO E LARGURA DA FAIXA DE APLICAÇÃO DA URÉIA NA RECUPERAÇÃO DO NITROGÊNIO PELA PLANTA DE MILHO'
}

\author{
Roberto Lyra Villas Bôas ${ }^{2 *}$; Antonio Enedi Boaretto ${ }^{3,4}$; Leonardo Theodoro Bull ${ }^{2,4}$; Irae Amaral \\ Guerrini ${ }^{2,4}$ \\ ${ }^{2}$ Depto. de Ciência do Solo - FCA/UNESP, C.P. 237 - CEP: 18603-970 - Botucatu, SP. \\ ${ }^{3}$ Laboratório de Nutrição Mineral de Plantas - CENA/USP, C.P. 96 - CEP: 13.400-970 - Piracicaba, SP. \\ ${ }^{4}$ Bolsista do CNPq. \\ *e-mail: rlvboas@fca.unesp.br
}

RESUMO: Com o objetivo de estudar o parcelamento e a largura da faixa de aplicação como meios para aumentar a recuperação pelo milho do nitrogênio da uréia aplicada em superfície, foi conduzido no ano agrícola 93/94, em um Latossolo Vermelho Escuro, em condições de campo, um experimento delineado em blocos ao acaso, com cinco repetições. Sete tratamentos foram utilizados: testemunha (sem $\mathrm{N}$ em cobertura); aplicação de $\mathrm{N}$ parcelada $\left(50 \mathrm{~kg} \mathrm{ha}^{-1}\right.$ de $\mathrm{N}$ aos 38 dias após semeadura - d.a.s e $50 \mathrm{~kg} \mathrm{ha}^{-1} \mathrm{de}$ $\mathrm{N}$ aos 60 d.a.s.) para faixas de 10, 20 e $40 \mathrm{~cm}$; aplicação de $N\left(100 \mathrm{~kg} \mathrm{ha}^{-1}\right.$ de $\mathrm{N}$ aos 38 d.a.s.) para faixas de 10 e $40 \mathrm{~cm}$ e, aplicação de $\mathrm{N}$ parcelada (50 kg de $\mathrm{N} / \mathrm{ha}$ aos 38 d.a.s. e $50 \mathrm{~kg} \mathrm{ha}^{-1}$ de $\mathrm{N}$ aos 60 d.a.s.) para faixa de $20 \mathrm{~cm}$ de largura, neste caso, uréia granulada. A aplicação de uréia parcelada em cobertura, em faixas de 10, 20 e $40 \mathrm{~cm}$ de largura, não afetaram a massa de matéria seca, o conteúdo, a quantidade e a recuperação do $\mathbf{N}$ pela planta de milho. A recuperação de $\mathbf{N}$ pela planta de milho foi maior para a aplicação de $220 \mathrm{~kg} \mathrm{ha}^{-1}$ de uréia em uma única aplicação em faixas de $10 \mathrm{~cm}$ de largura em relação a de $40 \mathrm{~cm}$. O parcelamento da uréia aumentou os valores de massa seca, conteúdo, quantidade e recuperação do $\mathbf{N}$ na planta de milho em relação a aplicação em uma única vez.

Palavras-chave: Zea mays, nitrogênio, uréia, aplicação em faixa

\section{SPLITTING AND WIDTH OF STRIP UREA APPLICATIONS AND THE RECOVERY OF NITROGEN BY MAIZE PLANTS}

ABSTRACT: In order to evaluate the nitrogen recovery by maize, following a surface application of urea, a trial was carried out during 1993/94 under field conditions, on a dark red latosol (oxisol). A randomized complete block statistical design was used, with seven treatments and five replications. The seven treatments were: control (no $\mathrm{N}$ ); three split $\mathrm{N}$ applications $\left(50 \mathrm{~kg} \mathrm{~N} \mathrm{ha}^{-1}\right.$ urea at 38 and 60 days after sowing) using 10, 20 or $40 \mathrm{~cm}$ width strips; two single $\mathrm{N}$ applications (100 $\mathrm{kg} \mathrm{N} \mathrm{ha}^{-1}$ urea at 38 days after sowing) using 10 or $40 \mathrm{~cm}$ width strips; and split $\mathrm{N}$ applications (50 kg N ha ${ }^{-1}$ urea at 38 and 60 days after sowing) using a $20 \mathrm{~cm}$ width strip (granular urea). The top dressing that was applied at two growth stages in 10, 20 or $40 \mathrm{~cm}$ width strips did not affect dry matter production, content, amount and recovery of $\mathrm{N}$ in the corn plant. Only when one urea application was made, the recovery of $\mathrm{N}$ from the corn plant was larger for the $10 \mathrm{~cm}$ of width in relation to $40 \mathrm{~cm}$. The split application increased significantly dry matter production, content, amount and recovery of $\mathrm{N}$ in the corn plant in one single application. Key words: Zea mays, nitrogen, urea, width-strip application

\section{INTRODUÇÃO}

A recuperação do nitrogênio proveniente dos fertilizantes pelas plantas é relativamente baixa, chegando em muitos casos a menos de 50\%. A baixa eficiência de recuperação aliada ao uso indiscriminado desse nutriente, além de aumentar o custo da cultura, tem causado problemas de poluição ambiental tanto na água como no ar (Rao et al., 1992).

Dentre as várias fontes nitrogenadas utilizadas na agricultura, a uréia é a mais comercializada no país (Associação Nacional para Difusão de Adubos e Corretivos Agrícolas, 1994), porém, tem-se verificado o baixo aproveitamento do nitrogênio dessa fonte pelas

${ }^{1}$ Parte da Tese de Doutorado do primeiro autor apresentada ao CENA/USP - Piracicaba, SP. 
culturas devido, principalmente, a perdas por volatilização de amônia, quando a uréia não é enterrada ou arrastada para o interior do solo pelas águas da chuva ou irrigação (Buresh et al., 1984; Rodrigues \& Kiehl, 1986; Mclnnes et al., 1986a).

A incorporação da uréia em subsuperfície pode diminuir as perdas por volatilização (Malhi \& Nyborg, 1979; Fenn \& Miyamoto, 1981; Rodrigues \& Kiehl, 1986). No entanto, esta prática é ainda pouco utilizada pelos agricultores na adubação nitrogenada em cobertura, quer seja pela falta de equipamentos adequados para fazêla, quer pelo dano que a incoporação do fertilizante pode promover no sistema radicular ou, ainda, o aumento do custo da aplicação.

Vários são os fatores que podem influenciar no potencial de perdas da amônia, podendo estes agirem de forma isolada ou combinada. Fatores ambientais como o teor de água do solo influenciam as perdas por volatilização, porém o seu estudo é complexo, uma vez que, em condições de campo, a dinâmica da água é muito variada (Hargrove, 1988).

A velocidade de hidrólise da uréia é outro fator que poderá influenciar nas perdas de nitrogênio. Essa velocidade, além de estar altamente correlacionada com as propriedades do solo como CTC, carbono orgânico e porcentagem de argila (Reynolds et al., 1985), também poderá ser afetada pelo modo de aplicação do fertilizante que modifique a concentração de uréia por volume de solo (Black et al., 1987; Hargrovre, 1988), o que pode ser conseguido alterando a largura de faixa de aplicação do fertilizante, o tamanho da partícula de uréia ou ainda a taxa de aplicação.

Hargrove \& Kissel (1979) obtiveram valores médios de perdas de amônia de $5 \%$ quando uma solução de uréia foi aplicada em área total, comparada à aplicação gotejada em faixa, na qual as perdas foram de $2 \%$ do $\mathrm{N}$, para uma taxa de aplicação de $112 \mathrm{~kg} \mathrm{ha}^{-1}$.

Fairlie \& Goos (1986) observaram que a perda de amônia aplicada em faixa foi menor em relação à aplicação em área total. A principal razão dessa diferença foi que na aplicação em faixa, devido à maior concentração de uréia, a hidrólise ocorreu mais lentamente. A aplicação em faixa pode resultar em aumento na produção de milho e recuperação de $\mathrm{N}$, comparada à aplicação em área total. Dados de Touchton \& Hargrove (1982); Eckert (1987); Fox \& Piekielek (1987) confirmam estes resultados para milho em sistema de semeadura direta.
Segundo Hargrove (1988), a aplicação em faixa, devido a uma lenta hidrólise da uréia, faz com que seja necessário um tempo maior para que toda a uréia se hidrolise, o que aumenta a probabilidade de ocorrência de chuva, nesse período de tempo, e poderá mover parte da uréia não hidrolisada para o interior do solo.

Dados de Malhi \& Nyborg (1979) evidenciam que a porcentagem de uréia hidrolisada, 14 dias após a aplicação, variou em seis diferentes solos estudados de 88 a $92 \%$, para uréia misturada ao solo, e de 74 a $78 \%$, para a uréia aplicada em faixa.

Com relação ao tamanho dos grânulos de uréia, trabalho de Volk (1959), em condições de laboratório, de Nommik (1973), em estudos com eucalipto, assim como para arroz (Singh \& Singh, 1988), na Ásia, tem sido observada de forma mais consistente a melhor eficiência do $\mathrm{N}$ da uréia granulada em relação à perolada.

Em outros trabalhos não se obteve efeito favorável pela aplicação da uréia granulada (Watkins et al., 1972; Buresh et al., 1984 e Villas Bôas, 1990). Há ainda na literatura trabalhos como o de Black et al. (1987), no qual a aplicação de grânulos de $8 \mathrm{~mm}$ de diâmetro resultou em aumento significativo de perdas comparada à aplicação de grânulos menores de uréia. O resultado obtido nesse último trabalho é atribuído a retenção sobre as folhas da pastagem de maior quantidade de uréia granulada em relação à perolada. Quando a uréia é retida sobre a superfície das folhas, as perdas de $\mathrm{N}$ por volatilização podem aumentar.

Katyal et al. (1988) obtiveram, também, diminuição na performace da uréia granulada em relação à perolada. Porém, atribuíram esse resultado às perdas por lixiviação de uréia não hidrolisada. Para Lara Cabezas et al. (1992), as maiores perdas de $\mathrm{N}$ estiveram relacionadas com uréia de maior tamanho de grânulo, possivelmente devido a alterações drásticas de $\mathrm{pH}$, junto ao grânulo, o que estaria favorecendo as perdas por volatilização.

O parcelamento da adubação nitrogenada tem por objetivo minimizar as perdas por lixiviação e aumentar a eficiência de uso do nitrogênio pela planta de milho (Cantarella, 1993). A princípio, o fornecimento parcelado de nitrogênio parece ser mais favorável, uma vez que menor quantidade de $\mathrm{N}$ ficará sujeito à lixiviação. Por outro lado, quando ocorre o parcelamento, menor concentração de $\mathrm{N}$ é aplicada por volume de solo. 
O presente trabalho teve como objetivo avaliar a recuperação do $\mathrm{N}$ da uréia pelo milho em função da largura de faixa de aplicação, do parcelamento e do tamanho do grânulo.

\section{MATERIAL E MÉTODOS}

O experimento foi instalado no campo, na Fazenda Experimental São Manuel, da Faculdade de Ciências Agronômicas, UNESP, "Campus" de Botucatu, localizada no município de São Manuel-SP. O solo foi classificado como Latossolo Vermelho Escuro, textura média (Espíndola et al. ,1972).

As principais características químicas do solo, obtidas de acordo com metodologia descrita por Raij et al. (1987) são: $\mathrm{pH}\left(\mathrm{CaCl}_{2}\right.$ $0,01 \mathrm{~mol} \mathrm{~L}^{-1}$ ) 5,$2 ; 13 \mathrm{~g} \cdot \mathrm{dm}^{-3}$ de $\mathrm{MO} ; 5 \mathrm{mg} \cdot \mathrm{dm}^{-3}$ de P- resina; cátions trocáveis em mmol $\cdot \mathrm{dm}^{-3}$ : 0,9 de $\mathrm{K}^{+} ; 9$ de $\mathrm{Ca}^{2+} ; 6$ de $\mathrm{Mg}^{2+} ; 17$ de $\mathrm{H}^{+}+\mathrm{Al}^{3+} ; 32$ mmol $\cdot \mathrm{dm}^{-3}$ de CTC ; $0,3 \mathrm{em} \mathrm{mg.dm}{ }^{-3}$ de $\mathrm{Zn}$ (DTPA); 0,7 de $B$ em $\mathrm{mg}^{\circ} \mathrm{dm}^{-3}$ e uma saturação por bases de $48 \%$.

A dose de calcário utilizada foi baseada na análise de solo, seguindo a recomendação de Raij et al. (1985), sendo aplicado o equivalente a $700 \mathrm{~kg} \mathrm{ha}^{-1}$ de calcário dolomítico (PRNT $=100 \%$ ).

Todos os tratamentos receberam 15-80$45 \mathrm{~kg} \mathrm{ha}^{-1}$ de $\mathrm{N}-\mathrm{P}_{2} \mathrm{O}_{5}-\mathrm{K}_{2} \mathrm{O}$ na adubação básica (Raij et al., 1985), utilizando como fontes o sulfato de amônio, superfosfato simples e cloreto de potássio, respectivamente. Também foi aplicado sulfato de zinco em quantidade equivalente a 4 $\mathrm{kg} \mathrm{ha}^{-1}$ de zinco.
O experimento foi instalado seguindo delineamento em blocos ao acaso, constando de 5 repetições e 7 tratamentos, conforme descrito na TABELA 1. A análise de variância foi desdobrada em contrastes ortogonais específicos. A parcela experimental constou de uma área total de $30 \mathrm{~m}^{2}$ (6 linhas de $5 \mathrm{~m}$ ) sendo que, como parcela útil, foram consideradas 2 linhas de 3 metros lineares.

O preparo do solo foi realizado de forma convencional e na semeadura utilizou-se o híbrido $\mathrm{XL}$ 678. Após o desbaste o estande foi padronizado em 6 plantas por metro.

A adubação nitrogenada em cobertura foi aplicada na dosagem de $100 \mathrm{~kg} \mathrm{ha}^{-1} \mathrm{de} \mathrm{N}$. Nos tratamentos de 2 a 6 a fonte utilizada foi a uréia comercial perolada apresentando diâmetro e peso médio de $1,5 \mathrm{~mm}$ e $6,5 \mathrm{mg}$, contendo 450 $\mathrm{g}$ de $\mathrm{N} \mathrm{kg}^{-1}$. No tratamento 7 foi aplicada a uréia granulada cujo grânulo apresentou, em média , $7,0 \mathrm{~mm}$ de diâmetro, massa de $250 \mathrm{mg}$ e a concentração de $460 \mathrm{~g}$ de N kg${ }^{-1}$.

A aplicação dos fertilizantes foi realizada em superfície, apenas em um dos lados da planta, sendo que, para que houvesse precisão quanto à largura da faixa de aplicação do fertilizante, foi colocado um gabarito de modo a limitar a largura da faixa.

A colheita ocorreu aos 137 dias após a semeadura. Nessa ocasião as plantas foram pesadas e, posteriormente, trilhados os grãos. $\mathrm{O}$ material coletado, após a separação das espigas, foi passado em desfibrador e, em seguida, foram retiradas amostras, que também foram pesadas e colocadas em estufa para secagem a $60^{\circ} \mathrm{C}$ até

TABELA 1 - Descrição dos tratamentos.

\begin{tabular}{|c|c|c|c|}
\hline \multirow[t]{2}{*}{ Modo de aplicação } & \multirow[t]{2}{*}{ Uréia } & \multicolumn{2}{|c|}{ quantidade aplicada de $\mathrm{N}$ em kg.ha-1 e épocas de aplicação } \\
\hline & & 38 d.a.s. ${ }^{(1)}$ & 60 d.a.s. \\
\hline T1- Testemunha & - & - & - \\
\hline T2- faixa de $10 \mathrm{~cm}^{(2)}$ & perolada & 50 & 50 \\
\hline T3- faixa de $20 \mathrm{~cm}$ & perolada & 50 & 50 \\
\hline T4- faixa de $40 \mathrm{~cm}$ & perolada & 50 & 50 \\
\hline T5- faixa de $10 \mathrm{~cm}$ & perolada & 100 & - \\
\hline T6- faixa de $40 \mathrm{~cm}$ & perolada & 100 & - \\
\hline T7- faixa de $20 \mathrm{~cm}$ & $\operatorname{granulada}^{(3)}$ & 50 & 50 \\
\hline
\end{tabular}

(1) dias após a semeadura

(2) uréia perolada aplicada numa faixa delimitada de $10 \mathrm{~cm}$ de largura, distante $5 \mathrm{~cm}$ do caule do milho.

(3) uréia granulada (grânulos com $7 \mathrm{~mm}$ de diâmetro). 
peso constante, para determinação da matéria seca e o conteúdo de $\mathrm{N}$.

A análise do conteúdo de $\mathrm{N}$ na planta de milho foi realizada pelo método semi-micro Kjeldahl, a partir do extrato obtido de $200 \mathrm{mg}$ de matéria seca com solução digestora de ácido sulfúrico e posterior destilação e titulação, de acordo com a técnica descrita por Bremner \& Edwards (1965).

Os cálculos de recuperação do $\mathrm{N}$ pela planta de milho foram realizados por meio do método indireto, considerando que a quantidade de $\mathrm{N}$ na testemunha representou o $\mathrm{N}$ proveniente do solo (natural) e o aplicado com a adubação de semeadura. A diferença da quantidade de $\mathrm{N}$ na testemunha em relação aos tratamentos (QNPPF) representa o $\mathrm{N}$ proveniente do adubo, conforme a seguinte expressão:

$$
\% \mathrm{R}=\frac{\mathrm{QNPPF}}{\mathrm{QNA}} \times 100
$$

em que : $Q N A=$ a quantidade de nitrogênio aplicada em $\mathrm{kg} \mathrm{ha}^{-1}$.

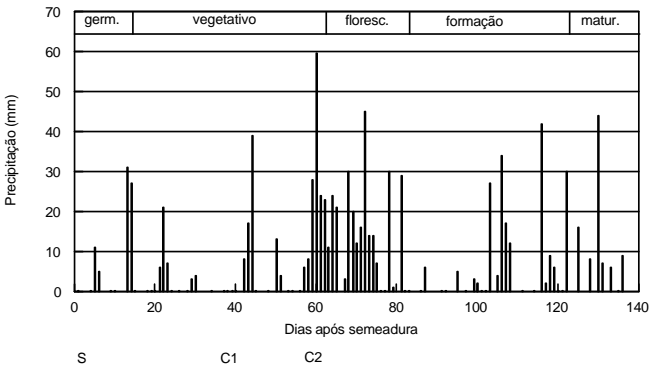

$\mathrm{S}=$ Semeadura; $\mathrm{C}=$ cobertura : 1 (38 d.a.s.), 2 (60 d.a.s.)

Figura 1 - Variação da precipitação durante o desenvolvimento da cultura do milho.

\section{RESULTADOS E DISCUSSÃO}

As chuvas foram relativamente freqüentes durante todo o ciclo da cultura sendo a precipitação do período de $900 \mathrm{~mm}$ (Figura 1). As adubações de cobertura foram aplicadas em condições diferentes de umidade de solo e precipitação. Antes da primeira cobertura, ocorreram 6 dias de estiagem, não havendo precipitação por mais 5 dias após a aplicação. A segunda cobertura foi antecedida de 9 dias de chuva, sendo que esta permaneceu por mais 8 dias.
$\mathrm{Na}$ TABELA 2 estão reunidos os resultados de massa seca, conteúdo de $\mathrm{N}$, quantidade de $\mathrm{N}$ e a porcentagem de recuperação do $\mathrm{N}$ na planta de milho, aos 137 d.a.s.

\section{Produção de massa de matéria seca}

Os maiores valores de massa seca de parte aérea e de grão foram obtidos para a aplicação parcelada em 2 vezes, em faixas de 40 $\mathrm{cm}$, sendo que este valor não diferiu estatisticamente em relação às faixas de 10 e 20 $\mathrm{cm}$. No entanto, nota-se que quando a uréia foi aplicada em uma única vez, em faixa de $10 \mathrm{~cm}$ de largura, a massa seca de parte aérea foi estatisticamente superior em relação à de $40 \mathrm{~cm}$.

A comparação dos tratamentos, onde uma ou duas aplicações de uréia em cobertura foram feitas $(\mathrm{T} 2+\mathrm{T} 4) \times(\mathrm{T} 5+\mathrm{T} 6)$, indica que quando se parcelou a adubação, o valor de massa seca, tanto para planta como um todo, como para os grãos, foi estatisticamente superior em relação a uma única aplicação. Para aplicação parcelada de uréia na faixa $20 \mathrm{~cm}$ não se observou diferença estatística de massa seca em relação aos tratamentos nos quais a uréia granulada e perolada foram utilizadas.

A adubação nitrogenada utilizada no experimento visava a uma produtividade de 4000 a $6000 \mathrm{~kg}$ de grãos por hectare. Portanto, a produtividade média obtida no experimento de $4598 \mathrm{~kg} \mathrm{ha}^{-1}$ (considerando a umidade de 13\%) está dentro da faixa esperada.

\section{Conteúdo de nitrogênio na parte aérea da planta de milho}

Para o conteúdo de $\mathrm{N}$ na parte aérea da planta de milho, as diferenças estatísticas entre os tratamentos acompanharam as variações observadas para massa seca de parte aérea e portanto, o conteúdo de $\mathrm{N}$ tanto no grão como na parte aérea da planta de milho foi superior para todos os tratamentos em relação à testemunha e para aplicação de uréia parcelada em comparação com a cobertura aplicada em uma única vez.

$\mathrm{O}$ conteúdo de $\mathrm{N}$ nos grãos está acima do encontrado por Villas Bôas (1990), porém se assemelha aos valores obtidos por Coelho et al. (1992), enquanto que a concentração de $\mathrm{N}$ na parte aérea é próxima a encontrada por Andrade et al. (1975); Villas Bôas (1990); Coelho et al. (1992). 
TABELA 2 - Quadrado médio de tratamento, coeficiente de variação e médias dos tratamentos com indicação de significância pelo teste $\mathrm{F}$.

\begin{tabular}{|c|c|c|c|c|c|c|c|c|}
\hline \multirow{2}{*}{ Tratamento } & \multicolumn{2}{|c|}{ Matéria seca kg.ha-1 } & \multicolumn{2}{|c|}{$\begin{array}{c}\text { Conteúdo de N } \\
\text { g. } \mathrm{kg}^{-1}\end{array}$} & \multicolumn{2}{|c|}{$\begin{array}{l}\text { Quantidade de } \\
\text { N kg.ha }{ }^{-1}\end{array}$} & \multicolumn{2}{|c|}{ Recuperação \% } \\
\hline & planta & grãos & Planta & Grãos & planta & grãos & planta & grãos \\
\hline QM tratamento & $* *$ & * & $* *$ & $* *$ & $* *$ & $* *$ & $* *$ & $* *$ \\
\hline CV (\%) & 12 & 21 & 6 & 6 & 14 & 24 & 40 & 32 \\
\hline Média Geral & 9760 & 4068 & 9,7 & 16,1 & 96 & 65 & 32 & 43 \\
\hline $\mathrm{QM}(\mathrm{T} 1 \mathrm{x}$ outros $)$ & ** & ** & ** & ** & $* *$ & $* *$ & - & - \\
\hline média T1 & $8158 \mathrm{~b}$ & 2979 b & $7,2 \mathrm{~b}$ & $13,1 \mathrm{~b}$ & $59 \mathrm{~b}$ & $39 \mathrm{~b}$ & - & - \\
\hline média outros & $10027 \mathrm{a}$ & $4250 \mathrm{a}$ & $10,4 \mathrm{a}$ & $16,7 \mathrm{a}$ & $102 \mathrm{a}$ & $69 a$ & - & - \\
\hline QM T2 $\times$ T3 $\times$ T4 & ns & ns & ns & ns & ns & ns & ns & ns \\
\hline média T2 & $9895 \mathrm{a}$ & $4167 \mathrm{a}$ & $10,4 \mathrm{a}$ & $17,5 \mathrm{a}$ & $104 \mathrm{a}$ & $64 \mathrm{a}$ & $33 \mathrm{a}$ & $45 \mathrm{a}$ \\
\hline média T3 & $10656 \mathrm{a}$ & $4505 \mathrm{a}$ & $10,3 \mathrm{a}$ & $16,8 \mathrm{a}$ & $110 \mathrm{a}$ & $76 \mathrm{a}$ & $37 \mathrm{a}$ & $52 \mathrm{a}$ \\
\hline média T4 & $10996 \mathrm{a}$ & 4936 a & $10,6 \mathrm{a}$ & $16,9 \mathrm{a}$ & $117 \mathrm{a}$ & $82 \mathrm{a}$ & $43 \mathrm{a}$ & $58 \mathrm{a}$ \\
\hline QM T5xT6 & * & ns & ns & ns & * & ns & * & ns \\
\hline média T5 & $10014 a$ & $4134 \mathrm{a}$ & $9,9 \mathrm{a}$ & $16,7 \mathrm{a}$ & $100 \mathrm{a}$ & $69 \mathrm{a}$ & $30 \mathrm{a}$ & $41 \mathrm{a}$ \\
\hline média T6 & 8099 b & $3147 \mathrm{a}$ & $9,5 \mathrm{a}$ & $16,0 \mathrm{a}$ & $76 \mathrm{~b}$ & $50 \mathrm{a}$ & $11 \mathrm{~b}$ & $18 \mathrm{~b}$ \\
\hline $\mathrm{QM}(\mathrm{T} 2+\mathrm{T} 4) \times(\mathrm{T} 5+\mathrm{T} 6)$ & * & * & $* *$ & * & $* *$ & * & ** & ** \\
\hline média $(\mathrm{T} 2+\mathrm{T} 4)$ & $10446 a$ & $4551 \mathrm{a}$ & $10,5 \mathrm{a}$ & $17,1 \mathrm{a}$ & $110 \mathrm{a}$ & $73 a$ & $38 \mathrm{a}$ & $52 \mathrm{a}$ \\
\hline média (T5+T6) & 9056 b & $3640 \mathrm{~b}$ & $9,7 \mathrm{~b}$ & $16,3 \mathrm{~b}$ & $88 \mathrm{~b}$ & $59 \mathrm{~b}$ & $20 \mathrm{~b}$ & $29 \mathrm{~b}$ \\
\hline QM T3xT7 & ns & ns & ns & ns & ns & ns & ns & ns \\
\hline Média T3 & $10656 \mathrm{a}$ & $4505 \mathrm{a}$ & $10,3 \mathrm{a}$ & $16,8 \mathrm{a}$ & $110 \mathrm{a}$ & $76 \mathrm{a}$ & $37 \mathrm{a}$ & $52 \mathrm{a}$ \\
\hline Média T7 & $10503 \mathrm{a}$ & $4610 \mathrm{a}$ & $10,2 \mathrm{a}$ & $16,4 \mathrm{a}$ & $106 \mathrm{a}$ & $76 \mathrm{a}$ & $37 \mathrm{a}$ & $48 \mathrm{a}$ \\
\hline
\end{tabular}

ns $=$ não significativo, ${ }^{*},{ }^{* *}=$ significativos a 5 e $1 \%$, respectivamente pelo teste $\mathrm{F}$. Médias seguidas das mesmas letras não diferem estatisticamente entre si.

\section{Quantidade de nitrogênio na parte aérea da planta de milho}

As quantidades de $\mathrm{N}$ extraídas pela planta de milho variaram de $59 \mathrm{~kg}$ de $\mathrm{N}$, para o tratamento testemunha, a $117 \mathrm{~kg}$ de $\mathrm{N}$ que foi obtido para o tratamento com duas aplicações em faixa de $40 \mathrm{~cm}$. Não se observaram diferenças significativas para quantidade de $\mathrm{N}$ na planta de milho entre as larguras de faixas $(10,20$ e 40 $\mathrm{cm}$ ), quando a uréia foi parcelada, no entanto, diferenças estatísticas foram observadas para a aplicação de apenas uma cobertura, em faixa de $40 \mathrm{~cm}$ em relação a de $10 \mathrm{~cm}$ de largura. Para esse parâmetro também não foram observadas diferenças entre os tratamentos com uréia granulada e perolada na faixa de $20 \mathrm{~cm}$.
Da quantidade total de nitrogênio extraída pela cultura, $68 \%$ em média encontravam-se nos grãos. Isso equivale a uma relação média entre $\mathrm{N}$ grão para $\mathrm{N}$ na parte aérea total de 0,68. Ulloa et al. (1982), utilizando dois híbridos de milho, obtiveram relação de 0,67 e 0,73 .

\section{Recuperação do nitrogênio aplicado pela parte aérea da planta de milho}

Os resultados de recuperação do nitrogênio pela parte aérea da planta de milho, indicam recuperação máxima de $58 \%$ para o tratamento em que foram realizadas duas aplicações em faixa de $40 \mathrm{~cm}$. Esse valor é semelhante aos encontrados em outros 
experimentos com milho (Neptune, 1977; Grove et al., 1980; França et al., 1986; Coelho et al., 1991), utilizando doses semelhantes de N. Diferenças significativas ocorreram somente quando foi realizada apenas uma aplicação de uréia em cobertura, sendo o maior valor de recuperação de $\mathrm{N}$ obtido para faixa mais estreita (10 $\mathrm{cm})$.

O parcelamento da cobertura, em duas vezes, promoveu aumento na recuperação do $\mathrm{N}$ em relação a uma única aplicação. Esses resultados podem estar indicando uma interação entre largura de faixa e número de aplicações, uma vez que ambos fatores influenciam a concentração de uréia no solo. Quando a aplicação foi parcelada em duas vezes, a largura da faixa não influenciou a recuperação de $\mathrm{N}$, possivelmente, porque a velocidade de hidrólise da uréia, em função da menor quantidade aplicada (111 kg ha-1 de uréia), foi semelhante para as várias larguras. No entanto, quando se aplicaram $222 \mathrm{~kg} \mathrm{ha}^{-1}$ de uréia em uma única vez, a largura da faixa afetou o aproveitamento, sendo que pode-se sugerir, para explicar o menor valor de recuperação obtido para a faixa de $40 \mathrm{~cm}$, uma hidrólise mais rápida da uréia que tenha gerado aumento de $\mathrm{pH}$ junto ao grânulo e, consequentemente, maiores perdas de $\mathrm{N}$ por volatilização.

No momento da primeira aplicação, a superfície do solo não recebia chuva há 6 dias sendo que essa condição permaneceu por mais 5 dias. O secamento do solo, segundo Mclnnes et al. (1986a; 1986b); Hargrove et al. (1987), é a situação em que ocorrem maiores perdas de nitrogênio.

A quantidade de urease no solo tem relação direta com o teor de argila e matéria orgânica (Reynolds et al., 1985). O solo utilizado neste experimento contém cerca de $15,5 \%$ de argila e $13 \mathrm{~g} \mathrm{dm}^{-3}$ de $\mathrm{MO}$, o que sugere ser um solo com baixa atividade de urease e reforça a hipótese de menor velocidade de hidrólise.

No caso da faixa de $10 \mathrm{~cm}$, a maior concentração de uréia por $\mathrm{cm}^{2}$ possivelmente tenha retardado a hidrólise devido ao excesso de uréia em relação a enzima urease, o que permitiu um tempo maior para que parte da uréia, ao penetrar no solo com a água de chuva, viesse a hidrolizar em profundidade e, consequentemente, diminuir as perdas de nitrogênio por volatilização. Esse efeito não foi observado para a aplicação parcelada da cobertura, possivelmente devido à dose de N, a cada aplicação, ser a metade
(112 kg ha-1) e também porque a segunda aplicação ocorreu num período bastante chuvoso, e a uréia nas várias larguras de faixa, foi incorpo-rada ao solo pela água de chuva. Essa hipótese encontra apoio nos trabalhos de Bouwmeester et al. (1985) e McInnes et al. (1986b).

\section{CONCLUSÕES}

- A aplicação parcelada de uréia em cobertura em faixas de 10, 20 e $40 \mathrm{~cm}$ de largura não afetaram a massa de matéria seca, o conteúdo, a quantidade e a recuperação do $\mathrm{N}$ pela planta de milho.

- A recuperação de $\mathrm{N}$ pela planta de milho foi maior para a aplicação de $220 \mathrm{~kg} \mathrm{ha}^{-1}$, em uma única aplicação de uréia, em faixas de $10 \mathrm{~cm}$ de largura em relação a de $40 \mathrm{~cm}$.

- O parcelamento da uréia aumentou os valores de massa seca, conteúdo, quantidade e recuperação do $\mathrm{N}$ na planta de milho em relação a aplicação em uma única vez.

\section{REFERÊNCIAS BIBLIOGRÁFICAS}

ASSOCIAÇÃO NACIONAL PARA DIFUSÃO DE ADUBOS E CORRETIVOS AGRÍCOLAS. Anuário estatístico do setor de fertilizantes. São Paulo, 1994. 156p.

ANDRADE, A.G.; HAAG, H.P.; OLIVEIRA, G.D. Acumulação diferencial de nutrientes por cinco cultivares de milho (Zea mays L.): I. Acumulação de macronutrientes. Anais da ESALQ, v.32, p.115-149, 1975.

BLACK, A.S.; SHERLOCK, R.R.; SMITH, N.P. Effect of urea granule size on ammonia volatilization from surface-applied urea. Fertilizer Research, v.11, p.87-96, 1987

BOUWMEESTER, R.J.; VLEK, P.L.G.; STUMPE, J.M. Effects of environmental factors on ammonia volatilization from a urea fertilizer soil. Soil Science Society of America Journal, v.49, p.376-381, 1985.

BREMNER, J.M.; EDWARDS, A.P. Determination on isotope-ratio analysis of different forms of nitrogen in soils. I. Apparatus and procedure for destination and determination of ammonium. Soil Science Society of America Proceedings, v.29, n.5, p.504-507, 1965.

BURESH, R.J.; VLEK, P.L.G.; STRUMPE, J.M. Labeled nitrogen fertilizer research with urea in the semi-arid tropics: I. Greenhouse studies. Plant and Soil, v.80, p.3-19, 1984.

CANTARELLA, H. Calagem e adubação do milho. In: BULL, L.T.; CANTARELLA, H. (Ed.) Cultura do milho. Piracicaba: Potafos, 1993. p.148-196. 
COELHO, A.M.; FRANÇA, G.E.; BAHIA, A.F.C.; GUEDES, G.A.A. Balanço de nitrogênio ${ }^{15} \mathrm{~N}$ em um Latossolo Vermelho-Escuro, sob vegetação de cerrado, cultivado com milho. Revista Brasileira de Ciência do Solo, v.15, n.2, p.187-193, 1991.

COELHO, A.M.; FRANÇA, G.E.; BAHIA, A.F.C.; GUEDES, G.A.A. Doses e métodos de aplicação de fertilizantes nitrogenados na cultura do milho sob irrigação. Revista Brasileira de Ciência do Solo, v.10, p.61-67, 1992.

ECKERT, D.J. UAN Management practices for notillage corn production. Journal of Fertilizer Issues, v.4, p.13-18, 1987.

ESPÍNDOLA, C.R.; CAMARGO, W.A.; PACCOLA, A.A. Levantamento de Solos da fazenda experimental São Manuel. In: JORNADA CIENTÍFICA DA FACULDADE DE CIÊNCIAS MÉDICAS E BIOLÓGICAS DE BOTUCATU, 2., Botucatu, 1972. Anais. Botucatu: UNESP, 1972. 35p.

FAIRLIE, T.E.; GOOS, R.J. Urea hydrolyses and ammonia volatilization characteristics of liquid fertilizer mixtures: II. Studies under modified field conditions. Journal of Fertilizer Issues, v.3, p.86-90, 1986.

FENN, L.B.; MIYAMOTO, S. Ammonia loss and associated reactions of urea in calcareous soils. Soil Science Society of America Journal, v.45, p.537-540, 1981.

FRANÇA, G.E.; BAHIA FILHO, A.F.C.; VASCONCELOS, C.A.; SANTOS, H.L. dos. Adubação nitrogenada em Minas Gerais. In: SIMPÓSIO SOBRE ADUBAÇÃO NITROGENADA NO BRASIL, 1., Ilhéus, 1985. Anais. Ilhéus: CEPLAC/SBCS, 1986. p.107-120.

FOX, R.H.; PEIKIELEK, W.P. Nitrogen fertilizer source and method and time of application effects on no-till corn (Zea mays L.) Journal of Fertilizer Issues, v.4, p.7-12, 1987.

GROVE, L.T.; RITCHEY, K.D.; NADERMAN JUNIOR, G.C. Nitrogen fertilization of maize on Oxisol of the cerrado of Brazil. Agronomy Journal, v.27, n.2, p.261-265, 1980.

HARGROVE, W.L. Soil, environmental, and management factors influencing ammonia volatilization under field conditions. In: BOCK, B.R.; KISSEL, D.E. (Ed.) Ammonia volatilization from urea fertilizers. Alabama: NFDC, TVA, 1988. cap. 2, p.17-36.

HARGROVE, W.L.; BLOCK, B.R.; BLOCK, R.A.; RAUNIKAR, R.A.; URBAN, W.J. Comparison of a forced-draft technique to ${ }^{15} \mathrm{~N}$ recovery for measuring ammonia volatilization under field conditions. Soil Science Society America Journal, v.51, p.124-128,1987.

HARGROVE, W.L.; KISSEL, D.E. Ammonia volatilization from surface applications of urea in the field and laboratory. Soil Science Society America Journal, v.43, p.359-363, 1979.
KATYAL, J.C.; BIJAY-SINGH; VLEK, P.L.G. Effect of granule size and the placement geometry on the efficiency of urea supergranules for wetland rice grown on a permeable soil. Fertilizer Research, v.15, p.193-201, 1988.

LARA CABEZAS, W.A.R.; TRIVELIN, P.C.O.; BOARETTO, A.E. Efeito do tamanho de grânulo e relação N/S da uréia aplicada em superfície na volatilização de amônia sob diferentes umidades iniciais do solo. Revista Brasileira de Ciência do Solo, v.16, p.409-413, 1992.

McINNES, K.J.; FERGUSON, D.E.; KISSEL, D.E.; KANEMASU, E.T. Field measurements of ammonia loss from surface applications of urea solution to bare soil. Agronomy Journal, v.78, p.192-196, 1986a.

McINNES, K.J.; FERGUSON, D.E.; KISSEL, D.E.; KANEMASU, E.T. Ammonia loss from applications of urea-ammonium nitrate solution to straw residue. Soil Science Society of America Journal, v.50, p.969-974, 1986b.

MALHI, S.S.; NYBORG, M. Rate of hydrolysis of urea as influenced by thiorea and pellet size. Plant and Soil, v.51, p.177-186, 1979.

NEPTUNE, A.M. Efeito de diferentes épocas e modos de aplicação do nitrogênio na produção do milho, na quantidade de proteína, na eficiência do fertilizante e na diagnose foliar, utilizando sulfato de amônio - ${ }^{15} \mathrm{~N}$. Anais da ESALQ, v.34, p.515-539, 1977.

NOMMIK, H. Assessment of volatilization loss of ammonia from surface-applied urea on forest soil by $\mathrm{N}^{15}$ recovery. Plant and Soil, v.38, p.589-603, 1973.

RAIJ, B.van; QUAGGIO, J.A.; CANTARELLA, H.; FERREIRA,M.E.; LOPES, A. S.; BATAGLIA, O.C. Análise química do solo para fins de fertilidade. Campinas: Fundação Cargill, 1987. $170 \mathrm{p}$.

RAIJ, B.van; SILVA,N.M.; BATAGLIA, O.C.; QUAGGIO, J.A.; HIROCE, R.; CANTARELLA, H.; BELLINAZZI JUNIOR; DECHEN, A.R.; TRANI, P.S. Recomendação de adubação e calagem para o estado de São Paulo. Campinas: IAC, 1985. 107p. (Boletim, 100).

RAO, A.C.S.; SMITH, J.L.; PARR, J.F.; PAPENDICK, R.I. Considerations in estimating nitrogen recovery efficiency by the difference and isotopic dilution methods. Fertilizer Research, v.33, p.209-217, 1992.

REYNOLDS, C.M.; WOLF, D.C.; ARMBRUSTER, J.A. Factors related to urea hydrolysis in soils. Soil Science Society of America Journal, v.49, p.104-108, 1985.

RODRIGUES, M.B.; KIEHL, J.C. Volatilização de amônia após emprego de uréia em diferentes doses e modos de aplicação. Revista Brasileira de Ciência do Solo, v.10, p.37-43, 1986. 
SINGH, G.R.; SINGH, T.A. Nitrogen movement and uptake by rice fertilized with urea supergranules in two contrasting Mollisols. Fertilizer Research, v.16, p.37-45, 1988.

TOUCHTON, J.T.; HARGROVE, W.L. Nitrogen sources and methods of application for no-tillage corn production. Agronomy Journal, v.74, p.823-826, 1982.

ULLOA, A.M.C.; LIBARDI, L.P.; REICHARDT, K. Utilização do nitrogênio por dois híbridos de milho. Campinas: Fundação Cargill, 1982.66p.

VILLAS BÔAS, R.L. Alternativas para aumento da recuperação do nitrogênio da uréia pelo milho (Zea mays L.). Piracicaba, 1990. 78p. Dissertação (Mestrado) - Centro de Energia Nuclear na Agricultura, Universidade de São Paulo.
VOLK, M.G. Volatile loss of ammonia following surface application of urea to turf of bare soils. Agronomy Journal, v.51, p.746-749, 1959.

WATKINS, S.H.; STRAND, R.D.; DE BELL, D.S.; $\mathrm{ESCH}, \mathrm{J}$. Factors influencing ammonia losses from urea applied to northwestern forest soils. Soil Science Society of America Proceedings, v.36, p.354-357, 1972.

Recebido para publicação em 19.03 .98

Aceito para publicação em 07.07.99 